\title{
Crystal - Rotator-I - Rotator-II Phase Transitions in the Mixtures of Alkanes
}

\section{Prabir K. Mukherjee*}

Department of Physics, Government College of Engineering and Textile Technology, 12 William Carey Road, Serampore, Hooghly-712201 India. E-mail: pkmuk1966@gmail.com

\section{ABSTRACT}

Using the combination of Flory-Huggins theory of isotropic mixing and Landau theory, we discuss the crystal - rotatorI - rotator-II phase transitions in the binary mixture of alkanes. The influence of concentration on the order parameters and the transition temperatures is discussed. Theoretical results show the first order character of both the rotator-I to crystal and rotator-II to rotator-I phase transitions in the mixture of alkanes. A good agreement between theoretical and experimental results are presented in this paper.

Keywords: Rotator Phases; Alkanes; Phase Transitions; Landau Theory

\section{Introduction}

Rotator phases are the states which exhibited by normal alkanes and alcohols consisting of layered structures with three dimensional crystalline order of the center of mass, but no long range orientational order of the molecules about their long axes. So far five different rotator phases have been identified with respect to the molecular arrangements: rotator-I $\left(\mathrm{R}_{\mathrm{I}}\right)$ phase, rotator-II ( $\left.\mathrm{R}_{\text {II }}\right)$ phase, rotator-III ( $\mathrm{R}_{\text {III }}$ ) phase, rotator-IV ( $\mathrm{R}_{\mathrm{IV}}$ ) phase and rotator-V $\left(R_{V}\right)$ phase ${ }^{[1-4]}$. The RI phase is composed of untilted molecules with respect to the layers and there is rectangularly distorted hexagonal lattice. The RII phase is described as composed of molecules that are untilted with respect to the layers that are packed in a hexagonal lattice. The $R_{V}$ phase is the same as the $R_{I}$ phase except that the molecules are tilted towards their next nearest neighbour (NNN).

Over the past few decades considerable experimental progress has taken place toward the understanding of the rotator phases and transitions among them ${ }^{[1-10]}$. There has been also a great deal of experimental studies on binary mixtures of alkanes ${ }^{[11-15]}$. Denicolo et al.$^{[11]}$ studied the rotator phase transitions for the binary mixtures of $\mathrm{C}_{23} \mathrm{H}_{48}+\mathrm{C}_{24} \mathrm{H}_{50}$. In pure form both the alkanes exhibit three rotator phases $R_{I}, R_{I I}, R_{V}$ including the crystalline phase (X). In this study they Copyright (C) 2020 Prabir K. Mukherjee doi: 10.24294/jpse.v3i1.1134

EnPress Publisher LLC.This work is licensed under the Creative Commons Attribution-NonCommercial 4.0 International License (CC BY-NC 4.0). http://creativecommons.org/licenses/ by/4.0/ only observed the $\mathrm{R}_{\mathrm{I}} \mathrm{X}$ and $\mathrm{R}_{\mathrm{II}}-\mathrm{R}_{\mathrm{I}}$ phase transitions although the $R_{V}$ phase was present in pure alkanes. So the $R_{V}$ phase is suppressed. It was observed that the $R_{I I-}$ $\mathrm{R}_{\mathrm{I}}$ transition temperature increases with the increase of the concentration of the second compound $\mathrm{C}_{24} \mathrm{H}_{50}$. However, the $\mathrm{R}_{\mathrm{I}}-\mathrm{X}$ transition temperature decreases with the increase of the concentration of $\mathrm{C}_{24} \mathrm{H}_{50}$. The lattice distortion changes with the change of concentration. Both the $\mathrm{R}_{\mathrm{I}} \mathrm{X}$ and $\mathrm{R}_{\mathrm{II}}-\mathrm{R}_{\mathrm{I}}$ phase transitions are observed to be first order transitions. Snyder et al. ${ }^{[12-13]}$ studied the phase separation and mixing in binary n-alkanes crystal phases. Sirota et al. ${ }^{[14-15]}$ studied the rotator phase transitions in the binary mixture of alkanes $\mathrm{C}_{23} \mathrm{H}_{48}+\mathrm{C}_{28} \mathrm{H}_{58}$ using $\mathrm{x}$-ray scattering. This binary mixture was found to exist RII, RI phases and an intervening mesophase was reported to be the hexatic phase. The stability of the RI phase increases with the increase of concentration, squeezing out of the RV phase. Dutta et al. ${ }^{[16]}$ also observed the hexatic phase in the same alkanes mixture $\mathrm{C}_{23} \mathrm{H}_{48}+\mathrm{C}_{28} \mathrm{H}_{58}$ but with nanometer confinement condition. Mixtures of alkanes with nanoparticles and liquid crystals were also studied extensively[17-20].

In our previous works ${ }^{[21-24]}$, we extensively studied the rotator phase transitions in the binary mixtures of alkane+alkane, alkane+nanoparticles and alkane+liquid crystal. The purpose of the present work is to study the 
rotator phase transitions in the binary mixture of alkanes $\mathrm{C}_{23} \mathrm{H}_{48}+\mathrm{C}_{28} \mathrm{H}_{58}$ with the combination of Flory-Huggins theory of isotropic mixing and Landau theory.

\section{Theory}

This paper considers the mixture of two alkanes $\mathrm{C}_{23} \mathrm{H}_{48}$ and $\mathrm{C}_{24} \mathrm{H}_{50}$. Pure $\mathrm{C}_{23} \mathrm{H}_{48}$ and $\mathrm{C}_{24} \mathrm{H}_{50}$ alkanes exhibit the four phases: crystalline phase $(\mathrm{X}), \mathrm{R}_{\mathrm{V}}$ phase, $\mathrm{R}_{\mathrm{I}}$ phase and $\mathrm{R}_{\text {II }}$ phase. The $\mathrm{X}$ phase exhibits a layered structure consisting of bilayer stacking of the lamellas. It has orthorhombic (distorted-hexagonal) packing within a layer as well as long range herringbone order of the rotational degrees of freedom of the backbones. Thus the $\mathrm{X}$ phase is described by herringbone order parameter $\psi$ and lattice distortion order parameter $\xi$. The $\mathrm{R}_{\mathrm{V}}$ phase is described by two order parameters: tilt angle $\theta$ and lattice distortion parameter $\xi$. The $\mathrm{R}_{\mathrm{I}}$ phase is described by lattice distortion parameter $\xi$. Thus three order parameters $\psi, \theta$ and $\xi$ are to describe the experimental results of the binary mixture $\mathrm{C}_{23} \mathrm{H}_{48}+\mathrm{C}_{24} \mathrm{H}_{50}$. This paper uses the combination of Flory-Huggins theory and Landau theory. Then the total free energy per unit volume of the $\mathrm{C}_{23} \mathrm{H}_{48}+\mathrm{C}_{24} \mathrm{H}_{50}$ mixture can be written as $F=\frac{N k_{B} T}{V}[\varphi \ln \varphi+(1-\varphi) \ln (1-\varphi)+\chi \varphi(1-\varphi)]+$ $(1-\varphi)\left[\frac{1}{2} a \xi^{2}-\frac{1}{3} b \xi^{3}+\frac{1}{4} c \xi^{4}+\frac{1}{2} \alpha \theta^{2}+\frac{1}{4} \beta \theta^{4}+\frac{1}{2} p \psi^{2}+\right.$ $\left.\frac{1}{4} q \psi^{4}+\frac{1}{2} \delta \theta^{2} \xi+\frac{1}{2} G \theta^{2} \xi^{2}+\frac{1}{2} \gamma \psi^{2} \xi+\frac{1}{2} H \psi^{2} \xi^{2}+\frac{1}{2} \eta \theta^{2} \psi^{2}\right]$

The terms in the first bracket represent the isotropic mixing of two components. The terms in the second bracket are the contribution of the order parameters of the $\mathrm{X}, \mathrm{R}_{\mathrm{V}}$, and $\mathrm{R}_{\mathrm{I}}$ phases. $k_{B}$ is the Boltzmann constant and $T$ is the absolute temperature. $\varphi$ and $(1-\varphi)$ are the volume fractions of $\mathrm{C}_{24} \mathrm{H}_{50}$ and $\mathrm{C}_{23} \mathrm{H}_{48} . \chi$ is known as Flory-Huggins interaction parameter and is function of temperature. We choose $b>, c>0, q>0$, and $\beta>0$ for the stability of the free energy (1). $G, H, \delta, \gamma$ and $\eta$ are coupling constants. $\delta$ and $\gamma$ are chosen negative to favour the $\mathrm{R}_{\mathrm{V}}$ and $\mathrm{X}$ phases over the $\mathrm{R}_{\mathrm{I}}$ phase. $G, H$ and $\eta$ is assumed to be positive. We assume $a=a_{0}\left(T-T_{1}^{*}\right)$, $\alpha=\alpha_{0}\left(T-T_{2}^{*}\right)$ and $p=p_{0}\left(T-T_{3}^{*}\right)$ with $a_{0}>0, \alpha_{0}>$ $0, p_{0}>0 . T_{1}^{*}, T_{2}^{*}$ and $T_{3}^{*}$ are the virtual transition temperatures and described by $T_{1}^{*}=T_{01}+u_{1}(1-\varphi)+$ $u_{2}(1-\varphi)^{2}, T_{2}^{*}=T_{02}+v_{1}(1-\varphi)+v_{2}(1-\varphi)^{2}, T_{3}^{*}=$
$T_{03}+w_{1}(1-\varphi)+w_{2}(1-\varphi)^{2}$. The free energy (1) describes four phases: (i) $\mathrm{X}$ phase (ii) $\mathrm{Rv}$ phase (iii) $\mathrm{R}_{\mathrm{I}}$ phase (iv) $R_{I I}$ phase. Thus the free energy (1) describes the following six transitions: (i) $\mathrm{R}_{I I}-\mathrm{R}_{\mathrm{I}}$; (ii) $\mathrm{R}_{\mathrm{II}}-\mathrm{R}_{\mathrm{V}}$; (iii) $\mathrm{R}_{\mathrm{I}}-\mathrm{R}_{\mathrm{V}}$; (iv) $\mathrm{R}_{\mathrm{I}} \mathrm{X}$; (v) $\mathrm{R}_{\mathrm{II}}-\mathrm{X}$ and (vi) $\mathrm{R}_{\mathrm{V}}-\mathrm{X}$. However the mixture $\mathrm{C}_{23} \mathrm{H}_{48}+\mathrm{C}_{24} \mathrm{H}_{50}$ shows only two $\mathrm{R}_{\mathrm{II}}-\mathrm{R}_{\mathrm{I}}$ and $\mathrm{R}_{\mathrm{I}}-\mathrm{X}$ transitions observed in experiment ${ }^{[11]}$. The presence of the cubic term $b$ describes the first order $\mathrm{R}_{\mathrm{I}}-\mathrm{X}$ and $\mathrm{R}_{\mathrm{II}}-\mathrm{R}_{\mathrm{I}}$ transitions.

Minimization of Eq. (1) with respect to $\theta$ and $\psi$ we get

$$
\begin{aligned}
& \theta^{2}=-\frac{\alpha+\delta \xi+G \xi^{2}+\eta \psi^{2}}{\beta} \\
& \psi^{2}=-\frac{p+\gamma \xi+H \xi+\eta \theta^{2}}{q}
\end{aligned}
$$

From Eqs. (2) and (3) it is clear that the conditions $\alpha+\delta \xi+G \xi^{2}+\eta \psi^{2}=0$ and $p+\gamma \xi+H \xi^{2}+\eta \theta^{2}=0$ define the boundary between the $\mathrm{R}_{\mathrm{I}}, \mathrm{X}$ and $\mathrm{R}_{\mathrm{V}}$ phases. The $\mathrm{R}_{\mathrm{V}}$ phase occur only for $\alpha+\delta \xi+G \xi^{2}+\eta \psi^{2}<0$. Since $\delta<0, G>0, \eta>0$. Further in the region of $\mathrm{R}_{\mathrm{V}}$ phase $\alpha<0$. So the existence of the RV phase occurs for $\alpha<0, \delta<0$. In general sign of the coupling constant $\delta$ can changes sign with change concentration. $\delta$ can become positive for higher value of the concentration of second compound. Then the condition $\alpha+\delta \xi+G \xi^{2}+\eta \psi^{2}<0$ does not hold any more. Then the $R_{V}$ phase disappears and subsequently the $\mathrm{R}_{\mathrm{I}} \mathrm{X}$ transition occurs. The experimental results ${ }^{[11]}$ show the disappearance of the $R_{V}$ phase in the binary mixture of $\mathrm{C}_{23} \mathrm{H}_{48}+\mathrm{C}_{24} \mathrm{H}_{50}$ even though the pure components exhibit the $\mathrm{R}_{\mathrm{I}}-\mathrm{R}_{\mathrm{V}}$ transition. We will now discuss on the $\mathrm{R}_{\mathrm{I}}-\mathrm{X}$ and $\mathrm{R}_{\mathrm{II}}-\mathrm{R}_{\mathrm{I}}$ transitions in the binary mixture $\mathrm{C}_{23} \mathrm{H}_{48}+\mathrm{C}_{24} \mathrm{H}_{50}$.

Now $\theta=0, \psi=0, \xi \neq 0$ is the solution of the $\mathrm{R}_{\mathrm{I}}$ phase. Then the free energy for the $R_{I I}-R_{I}$ phase transition can be written as

$$
\begin{aligned}
& F_{R I}=\frac{N k_{B} T}{V}[\varphi \ln \varphi+(1-\varphi) \ln (1-\varphi)]+\chi \varphi(1-\varphi) \\
& +(1-\varphi)\left[\frac{1}{2} \alpha \xi^{2}-\frac{1}{3} b \xi^{3}+\frac{1}{4} c \xi^{4}\right]
\end{aligned}
$$

The conditions for the first order $R_{I I}-R_{I}$ phase transition is given by

$$
F_{R I}(\xi, \varphi)=F_{R I I}(\varphi), F_{R I}^{\prime}(\xi, \varphi)=0, F_{R I}^{\prime \prime}(\xi, \varphi) \geq 0
$$


In addition, the chemical potentials in the $\mathrm{R}_{\mathrm{I}}$ and $\mathrm{R}_{\mathrm{II}}$ phases are equivalent i.e $\mu_{R I I}=\mu_{R I}$.

$\theta=0, \psi \neq 0, \xi \neq 0$ is the solution of the $\mathrm{X}$ phase. Then the free energy for the $\mathrm{R}_{\mathrm{I}}-\mathrm{X}$ phase transition in terms of $\xi$ can be written as

$$
\begin{aligned}
& F_{X}=\frac{N k_{B} T}{V}[\varphi \ln \varphi+(1-\varphi) \ln (1-\varphi)+\chi \varphi(1-\varphi)] \\
& +(1-\varphi)\left[-\frac{p^{2}}{4 q}-\frac{H p}{q} \xi+\frac{1}{2} a^{*} \xi^{2}-\frac{1}{3} b^{*} \xi^{3}+\frac{1}{4} c^{*} \xi^{4}\right]
\end{aligned}
$$

Where

$b^{*}=\mathrm{b}-\frac{3 \gamma H}{q}$

$$
a^{*}=a-\frac{\gamma^{2}}{q}-\frac{H p}{q}
$$

$$
c^{*}=c-\frac{H^{2}}{q}
$$

The conditions for the first order $\mathrm{R}_{\mathrm{I}} \mathrm{X}$ phase transition is expressed as

$F_{X}(\xi, \varphi)=F_{R I}(\xi, \varphi), F_{X}^{\prime}(\xi, \varphi)=0, F_{X}^{\prime \prime}(\xi, \varphi) \geq 0$

Further, the chemical potentials in the $\mathrm{R}_{\mathrm{I}}$ and $\mathrm{X}$ phases are equivalent i.e $\mu_{R I}=\mu_{X}$.

Solving Eqs. (5) and (7) simultaneously one can observe the phase diagram showing $R_{I}-X$ and $R_{I I}-R_{I}$ phase transitions respectively.

\section{Results and discussion}

This paper now discusses our theoretical results by plotting various figures. Figures $\mathbf{1}$ and $\mathbf{2}$ show the temperature dependence of the order parameters $\xi$ and $\psi$ for different concentration of $\mathrm{C}_{24} \mathrm{H}_{50}$ in the $\mathrm{RI}$ and $\mathrm{X}$ phases respectively. This is done for a particular set of parameter values. It is clear from Figures 1 and 2 that both the order parameters $\xi$ and $\psi$ vary discontinuously with temperature both for pure compound as well as for the mixture of $\mathrm{C}_{23} \mathrm{H}_{48}+\mathrm{C}_{24} \mathrm{H}_{50}$. Figure 1 shows the increase of the lattice distortion parameter $\xi$ with the increase of the concentration of $\mathrm{C}_{24} \mathrm{H}_{50}$. From Figure 1, we observe that the jump of the lattice distortion order parameter for the $\mathrm{R}_{\mathrm{II}}-\mathrm{R}_{\mathrm{I}}$ transition increases from $\xi_{\mathrm{RII}-\mathrm{RI}}=0.26$ at $T_{\mathrm{RII}-\mathrm{RI}}=38.4{ }^{\circ} \mathrm{C}$ for $\varphi=0$ to $\xi_{\mathrm{RII}-\mathrm{RI}}=$ 0.3 at $T_{\mathrm{RII}-\mathrm{RI}}=39{ }^{\circ} \mathrm{C}$ for $\varphi=0.3$. This behaviour indicates the strong first order character of the $R_{I I}-R_{I}$ transition even in the binary mixture of alkanes. Figure 2 shows the decrease of the herringbone order parameter $\psi$ with the increase of the concentration of $\mathrm{C}_{24} \mathrm{H}_{50}$. From

Figure 2, we observe that the jump of the herringbone order parameter for the $\mathrm{R}_{\mathrm{I}}-\mathrm{X}$ transition changes from $\psi_{\mathrm{RII}-\mathrm{RI}}=0.078$ at $T_{\mathrm{RI}-\mathrm{X}}=29.7{ }^{\circ} \mathrm{C}$ for $\varphi=0$ to $\psi_{\mathrm{RII}-\mathrm{RI}}=0.022$ at $T_{\mathrm{RI}-\mathrm{X}}=28{ }^{\circ} \mathrm{C}$ for $\varphi=0.3$. This behaviour indicates the weak first order character of the $\mathrm{R}_{\mathrm{I}}-\mathrm{X}$ transition in the binary mixture of alkanes. This observation clearly indicates the possibility of the critical point $\varphi>0.3$ at the $\mathrm{R}_{\mathrm{I}}-\mathrm{X}$ transition in the binary mixture of alkanes. Temperature vs. concentration curve is shown in Figure 3. Figure 3 shows that the $R_{I I}-R_{I}$ transition temperature increases with the increase of concentration of $\mathrm{C}_{24} \mathrm{H}_{50}$. The RI-X transition temperature decreases with the increase of concentration of $\mathrm{C}_{24} \mathrm{H}_{50}$. The above theoretical analysis supports the experimental results ${ }^{[11]}$.

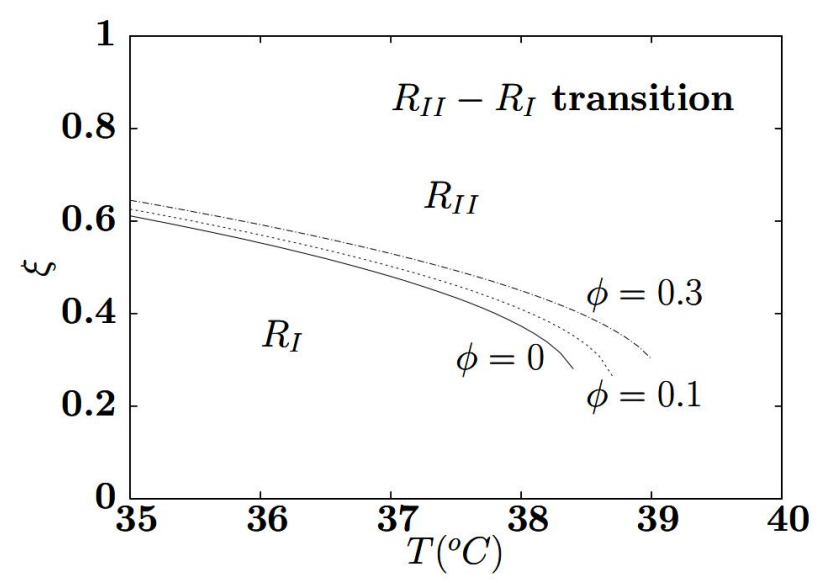

Figure 1. Temperature dependence of the lattice distortion parameter $\xi$ for different concentration of $\mathrm{C}_{24} \mathrm{H}_{50}$ in the $\mathrm{R}_{\mathrm{I}}$ phase of the $\mathrm{R}_{\mathrm{II}}-\mathrm{R}_{\mathrm{I}}$ transition.

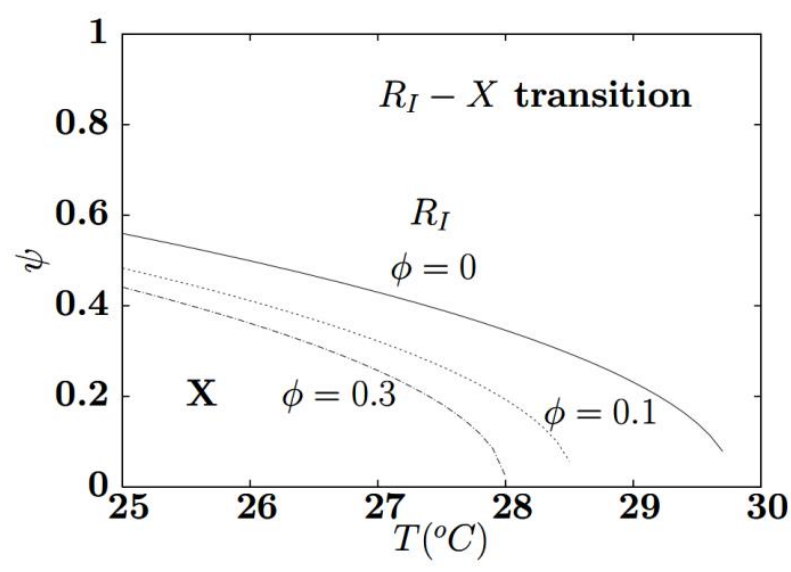

Figure 2. Temperature dependence of the herringbone order parameter $\psi$ for different concentration of $\mathrm{C}_{24} \mathrm{H}_{50}$ in the $\mathrm{X}$ phase of the $\mathrm{R}_{\mathrm{I}}-\mathrm{X}$ transition. 


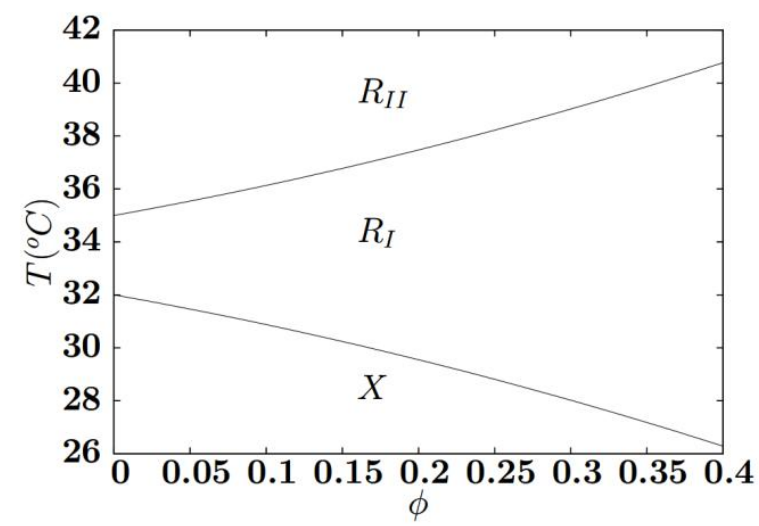

Figure 3. Temperature vs. concentration curve for the mixture of $\mathrm{C}_{23} \mathrm{H}_{48}+\mathrm{C}_{24} \mathrm{H}_{50}$.

\section{Conclusion}

This paper studies the $\mathrm{R}_{\mathrm{I}}-\mathrm{X}$ and $\mathrm{R}_{\mathrm{II}}-\mathrm{R}_{\mathrm{I}}$ transitions for the binary mixture of $\mathrm{C}_{23} \mathrm{H}_{48}+\mathrm{C}_{24} \mathrm{H}_{50}$. The theoretical analysis is based on free energy expansion using the combination of Flory Huggins theory and Landau theory. Theoretical results show that both the $\mathrm{R}_{\mathrm{I}} \mathrm{X}$ and $\mathrm{R}_{\mathrm{II}}-\mathrm{R}_{\mathrm{I}}$ transitions are first order even in the mixture of $\mathrm{C}_{23} \mathrm{H}_{48}+\mathrm{C}_{24} \mathrm{H}_{50}$. The possibility of the critical point at the $\mathrm{R}_{\mathrm{I}}-\mathrm{X}$ transition in the binary mixture of alkanes are also observed.

\section{References}

1. Ungar G. Structure of rotator phases in n-alkanes. J. Phys. Chem. 1983; 87: 689-695. doi: $10.1021 / \mathrm{j} 100227 \mathrm{a} 032$.

2. Sirota EB, King Jr. HE, Singer DM, et al. Rotator phases of the normal alkanes: An x-ray scattering study. J. Chem. Phys. 1993; 98: 5809-5824. doi: 10.1063/1.464874.

3. Sirota EB, Singer DM. Phase transitions among the rotator phases of the normal alkanes. J. Chem. Phys. 1994; 101: 10873-10882. doi: 10.1063/1.467837.

4. Sirota EB. Remarks concerning the relation between rotator phases of bulk n-alkanes and those of Langmuir monolayers of alkyl-chain surfactant on water. Langmuir 1997; 13: 3849-3859. doi: 10.1021/la9702291.

5. Doucet J, Denicolo I, Craievich A. X-ray study of the rotator phase of the odd-numbered paraffins $\mathrm{C}_{17} \mathrm{H}_{36}, \mathrm{C}_{19} \mathrm{H}_{40}$, and $\mathrm{C}_{21} \mathrm{H}_{44}$. J. Chem. Phys. 1981; 75: 1523-1529. doi: 10.1063/1.442185.

6. Craievich A, Denicolo I, Doucet J. Molecular motion and conformational defects in oddnumbered paraffins. Phys. Rev. B 1984; 30 47824788. doi: 10.1103/PhysRevB.30.4782.

7. Kruger J K, Jimenez R, Bohn K -P, et al. Phasetransition behavior of $n$-alkanes on nanostructured polytetrafluorethylens films: Brillouin spectroscopic and calorimetric investigations on pentacosane. Phys. Rev. B 1997; 56: 8683-8690. doi: 10.1103 /physrevb.56.8683.

8. Paoloni S, Mercuri F, Zammit U, et al. Analysis of rotator phase transitions in the linear alkanes hexacosane to triacontane by adiabatic scanning calorimetry and by photopyroelectric calorimetry. J. Chem. Phys. 2018; 148: 094503-1-10. doi: 10.1063/1.5020146.

9. Dutta S and Prasad SK. Confinement-driven radical change in a sequence of rotator phases: a study on n-octacosane. Phys. Chem. Chem. Phys. 2018; 20: 24345-24352. doi: 10.1039/c8cp03603a.

10. Mukherjee PK. Phase transitions among the rotator phases of the normal alkanes: A review. Phys. Rep. 2015; 588: 1-54. doi: 10.1016/j.physrep.2015.05.005.

11. Denicolo I, Craievich AF, Doucet J. X-ray diffraction and calorimetric phase study of a binary paraffin: $\mathrm{C}_{23}-\mathrm{C}_{48}-\mathrm{C}_{24} \mathrm{H}_{50}$. J. Chem. Phys. 1984; 80 : 6200-6203. doi: 10.1063/1.446722.

12. Ungar G, Masic N. Order in the rotator phase of nalkanes. J. Phys. Chem. 1985; 89:1036-1042. doi: 10.1021/j100252a030.

13. Snyder RG, Goh MC, Srivatsavoy VIP, et al. Measurement of the growth kinetics of microdomains in binary n-alkane solid solutions by infrared spectroscopy. J. Phys. Chem. 1992; 96: 10008-10019. doi: 10.1021/j100203a078.

14. Snyder RG, Conti G, Strauss HL et al. Termallyinduced mixing in partially microphase segregated binary n-alkane crystals. J. Phys. Chem. 1993; 97 : 7342-7350. doi: 10.1021/j100130a037.

15. Sirota EB, King HE, Hughes Jr. GJ, et al. Novel phase behavior in normal alkanes. Phys. Rev. Lett. 1992; 68: 492-495. doi: 10.1103/PhysRevLett.68.492.

16. Sirota EB, King HE Jr., Shao Henry H, et al. Rotator phases in mixtures of n-alkanes. J. Phys. Chem. 1995; 99: 798-804. doi: 10.1021/j100002a050.

17. Dutta S, Srikanthamurthy S, Mukherjee PK, et al. Nanometer confinement-driven promotion and stabilization of a hexatic phase intervening between ordered rotator phases. J. Phys. Chem. B. 2018; 122(48): 10953-10963.

doi: 10.1021/acs.jpcb.8b09017.

18. Kumar MV, Prasad SK. Influence of quenched disorder created by nanosilica network on phase transitions in tetracosane. RSC Adv. 2012; 2: 85318538. doi: $10.1039 / \mathrm{c} 2$ ra21480f.

19. Zammit U, Marinelli M, Mercuri F, et al. Effect of quenched disorder on the R1-RV, RII-RI and Liquid-RII rotator phase transition in alkanes. J. Phys. Chem. B. 2011; 115: 2331-2337. doi: 10.1021/jp111067z.

20. Kumar MV, Prasad SK, Rao DSSS, et al. Competition between anisometric and aliphatic entities: an unusual phase sequence with the induction of a phase in an $n$-alkane-liquid crystal 
binary system. Langmuir. 2014; 30: 4465-4473. doi: 10.1021/la500367y.

21. Mukherjee PK. Landau model of the $R_{I I}-R_{I}-R_{V}$ rotator phases in mixtures of alkanes. J. Chem. Phys. 2007; 127: 074901-1-6. doi: 10.1063/1.2764483.

22. Mukherjee PK. Tricritical behavior of the $\mathrm{R}_{\mathrm{I}}-\mathrm{R}_{\mathrm{V}}$ rotator phase transition in a mixture of alkanes with nanoparticles. J. Chem. Phys. 2011; 135: 134505-16. doi: $10.1063 / 1.3646213$.
23. Mukherjee PK. Effect of liquid crystal solute on the rotator phase transitions of n-alkanes. RSC Adv.. 2015; 5:12168-12177. doi: 10.1039/C4RA14116D.

24. Mukherjee PK. Effect of nanoparticles on the $\mathrm{R}_{\mathrm{II}^{-}}$ $\mathrm{R}_{\mathrm{I}}-\mathrm{R}_{\mathrm{V}}$ rotator phase transitions of alkane. Chem. Phys. Lett. 2017; 681: 75-79. doi: 10.1016/j.cplett.2017.05.038. 